- autoerotic, esoteric, and other sexual practices;

- commercial sex;

- sexual coercion;

- reproductive experiences;

- contraceptive experiences,

- safer sex and condom use;

- condom failure;

- history of and knowledge about sexually transmitted infections and blood-borne viruses;

- injecting and sexual risk behaviour.

The Australian Study of Health and Relationships is the largest and most comprehensive survey of sexuality ever undertaken in this country. It will provide important information to guide policy and practice for years to come.

\section{HOWTO GET A COPY}

Copies of the full report are available from the Australian Research Centre in Sex, Health and Society at the cost of A \$30. Cheques payable to 'ARCSHS' should be sent to Sex in Australia, Australian Research Centre in Sex, Health and Society, La Trobe University, Level 1, 215 Franklin Street, Melbourne VIC 3000. Alternately, requests can be made by email at arcshs@latrobe.com.au or by visiting the website www.latrobe.edu.au/arcshs.

\title{
CONTINUOUS NSW HEALTH SURVEY: QUARTERLY REPORT ON HEALTH STATUS, HEALTH BEHAVIOURS, AND RISK FACTORS
}

Lara Harvey, Andrew Hayen, and Margo Eyeson-Annan Centre for Epidemiology and Research NSW Department of Health

This is the first of a series of quarterly reports on the surveillance of the health status, health behaviours, and risk factors of the people of NSW, which will be produced from the Continuous NSW Health Survey. Ten indicators have been selected for inclusion in the report. These have been chosen either because they are of ongoing interest or because seasonal variation is possible (Figure 1). The Continuous NSW Health Survey is conducted by the Centre for Epidemiology and Research, through the Department of Health's Computer Assisted Telephone Interviewing (CATI) facility. The data reported in this report are based on the respondents described in Table 1. Although prevalence estimates are only shown in the graphs, 95 per cent confidence intervals have been calculated and these are available on request from the NSW Health Survey Program.

\section{SELF-RATED HEALTH}

Self-rated health is believed to principally reflect physical problems and, to a lesser extent, health behaviours and mental health problems. Longitudinal studies have shown that self-rated health is a strong and independent predictor of subsequent illness and premature death. ${ }^{1}$ In 2002 , 82.0 per cent of NSW residents aged 16 years and over reported their health as being either 'excellent', 'very

\section{TABLE 1}

RESPONDENTS AGED 16 YEARS AND OVER BY COLLECTION QUARTER

\begin{tabular}{|c|c|c|c|}
\hline Quarter & Males & Females & Persons \\
\hline February-March 2002 & 386 & 609 & 995 \\
\hline April-June 2002 & 1444 & 1993 & 3437 \\
\hline July-September 2002 & 1768 & 2345 & 4113 \\
\hline October-December 2002 & 1645 & 2266 & 3911 \\
\hline
\end{tabular}

Source: NSW Health Survey Program, Centre for Epidemiology and Research, NSW Department of Health. 


\section{FIGURE 1}

QUARTERLY REPORT OF SELECTED INDICATORS, CONTINUOUS NSW HEALTH SURVEY, MARCH 2002 TO DECEMBER 2002

$$
\rightarrow \text {-Males } \triangle \text { Females }
$$
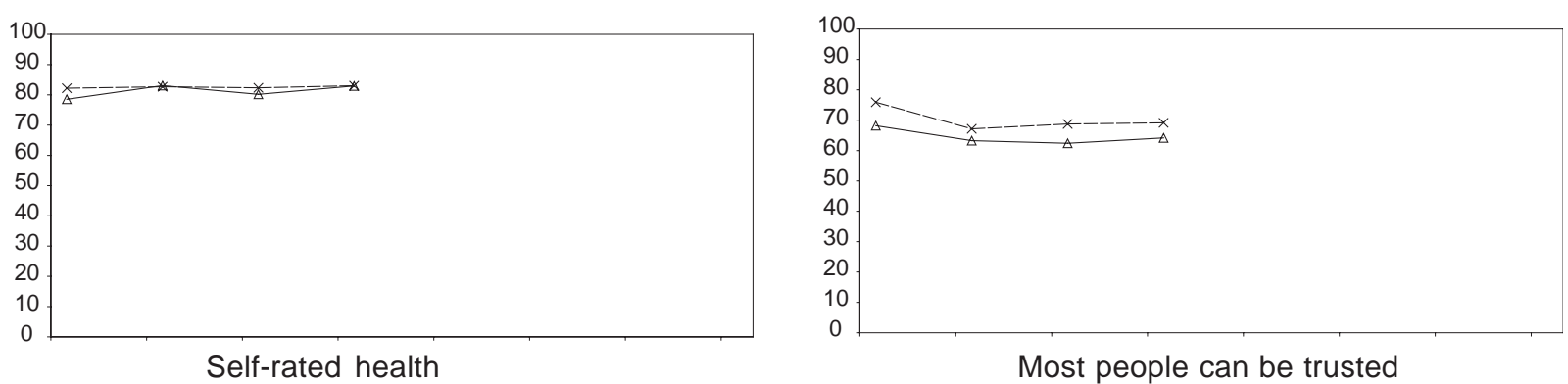

Most people can be trusted
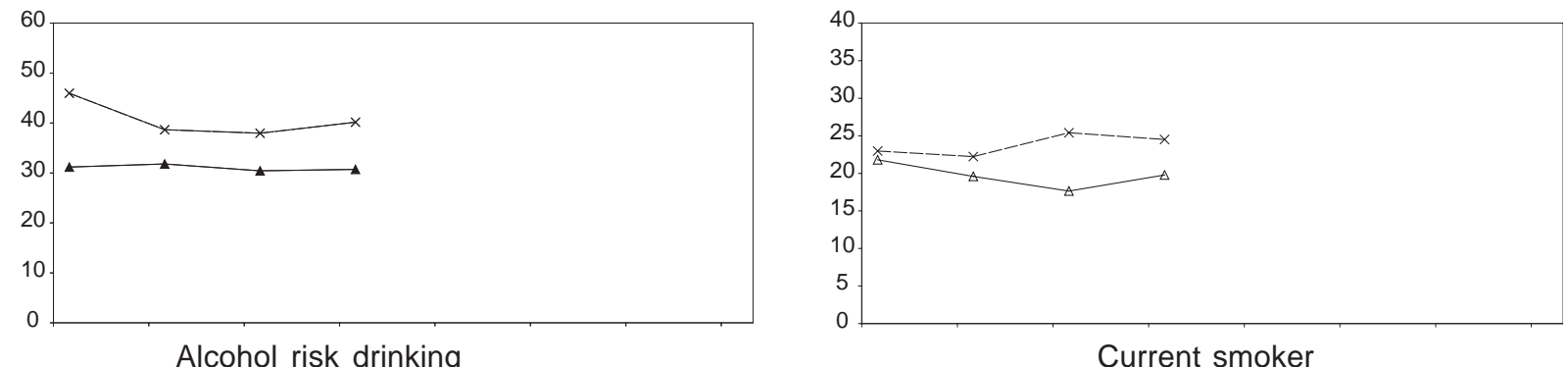

Current smoker
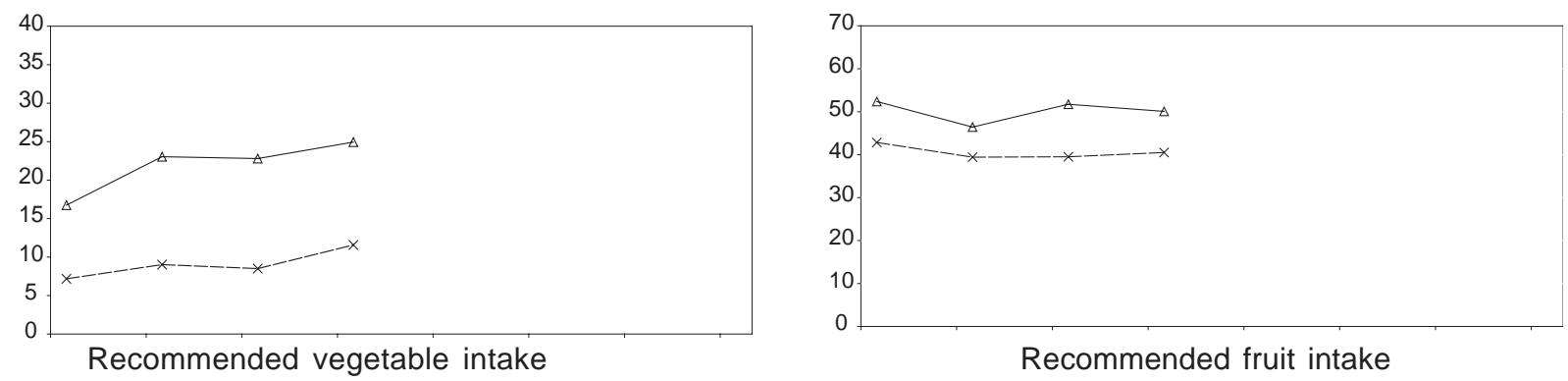

Recommended fruit intake
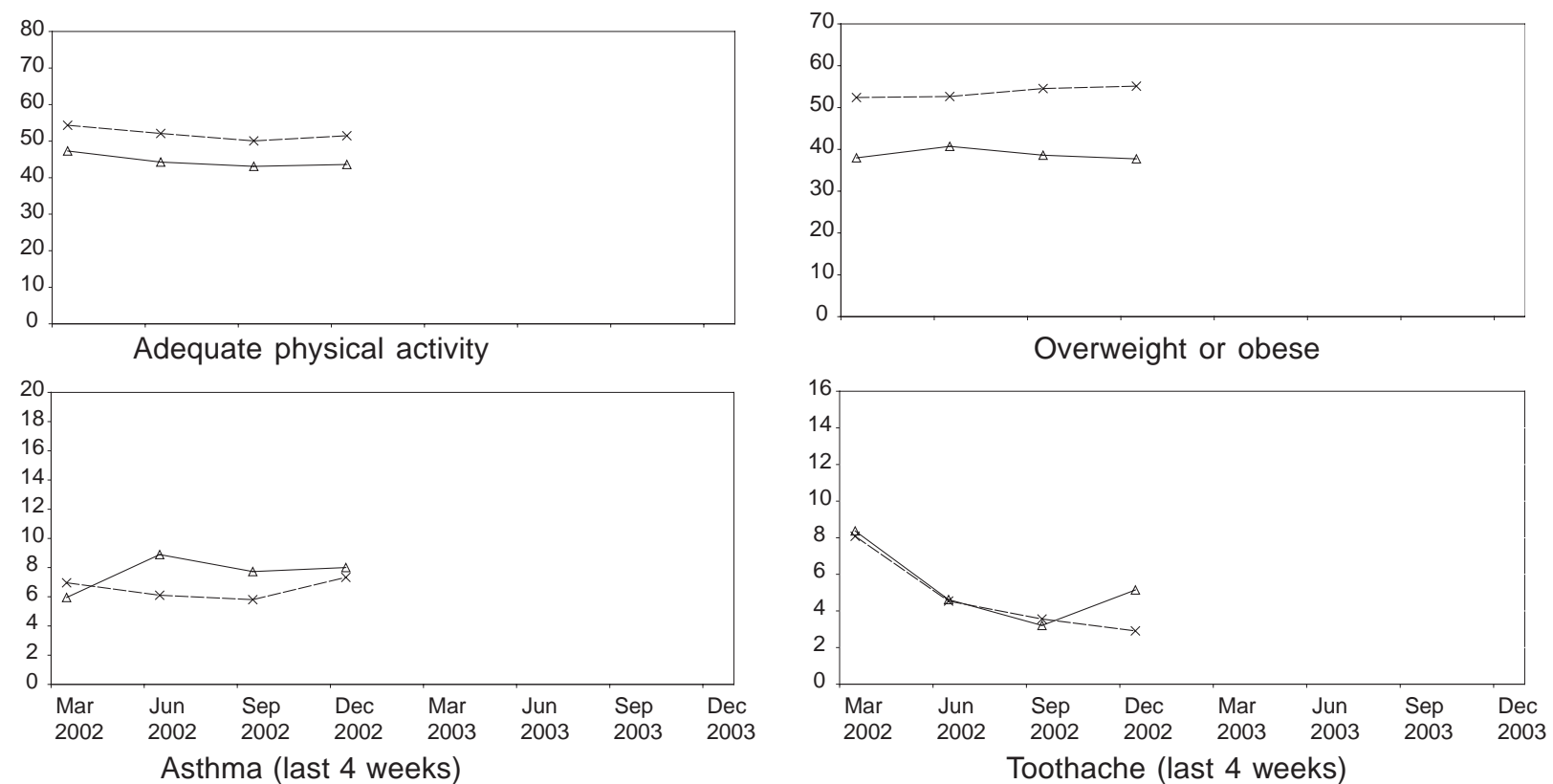

Source: NSW Health Survey Program, Centre for Epidemiology and Research, NSW Department of Health. 
good', or 'good'. There was no significant difference in self rated health between male rates ( 82.8 per cent) and female rates ( 81.2 per cent) between quarters.

\section{MOST PEOPLE CAN BE TRUSTED}

Trust involves a willingness to take risks in a social context. This willingness is based on a confidence that others will respond as expected and will act in mutually supportive ways - or at least will not attend harm. In 2002, 65.8 per cent of NSW residents either 'agreed' or 'strongly agreed' that most people can be trusted. Significantly fewer females (62.5 per cent) than males (69.1 per cent) agreed that most people can be trusted.

\section{ALCOHOL RISK DRINKING}

Risk drinking behaviour includes one or more of the following, consuming alcohol every day, consuming on average more than four (if male) or two (if female) standard drinks, or consuming more than six (if male) or four (if female) standard drinks on any one occasion or day. ${ }^{2}$ In 2002, 34.4 per cent of residents reported undertaking risk drinking behaviours. Males (39.2 per cent) reported significantly higher rates of risk drinking than females (29.7 per cent).

\section{CURRENT SMOKER}

Current smoking includes 'current' and 'occasional' smoking rates. In 2002, 21.4 per cent of respondents reported current smoking. Males (23.9 per cent) reported higher smoking rates than females (18.9 per cent).

\section{RECOMMENDED VEGETABLE INTAKE}

The recommended daily vegetable intake is four serves for females over 12 years of age, and males 12-18 years of age, and over 60 years. Five serves are recommended for males aged 19-60 years. ${ }^{3}$ In 2002, only 16.2 per cent of people consume the recommended quantities of vegetables. A significantly greater proportion of females (22.9 per cent) than males (9.2 per cent) eat the recommended amount of vegetables.

\section{RECOMMENDED FRUIT INTAKE}

The recommended daily fruit intake is three serves for people 12-18 years of age and two serves for people 19 years of age and over. ${ }^{3}$ In 2002, 45.3 per cent of NSW residents consumed the recommended amount of fruit. A significantly greater proportion of females (50.1 per cent) than males ( 40.3 per cent) eat the recommended quantities of fruit.

\section{ADEQUATE PHYSICAL ACTIVITY}

To maintain health it is currently recommended that moderate intensity exercise is carried out on all or most days of the week for at least 30 minutes per day. 'Adequate' physical activity is defined as a total of 150 minutes per week over five separate occasions. ${ }^{4}$ In $2002,46.6$ per cent of people undertook adequate physical activity. Significantly more males (50.4 per cent) than females (42.9 per cent) reported undertaking adequate physical activity.

\section{OVERWEIGHT OR OBESE}

Self-reported height and weight were used to estimate body mass index (BMI), which was used to classify respondents into body weight categories. A BMI of 25 to less than 30 is classified as overweight, and a BMI of equal to or greater than 30 as obese. In 2002, 46.3 per cent of people were classified as overweight or obese. Significantly more males (53.9 per cent) than females (38.5 per cent) were overweight or obese.

\section{ASTHMA}

In 2002, 7.1 per cent of people reported having asthma symptoms or seeking management for asthma in the last four weeks. There was no significant difference in asthma rates between males (6.5 per cent) and females (7.6 per cent) between quarters.

\section{TOOTHACHE}

In 2002, 5.1 per cent of people had a toothache 'often' or 'very often' in the last four weeks. There was no significant difference in toothache rates between males ( 4.8 per cent) and females (5.3 per cent) between quarters.

\section{REFERENCES}

1. Krause NM and Jay GM. What do global self-rated health items measure? Medical Care 1994; 32: 930-942.

2. National Health and Medical Research Council. Australian Alcohol Guidelines: Health risks and Benefits. Canberra, NHMRC, 2001.

3. National Health and Medical Research Council. Dietary Guidelines for Australian Adults. Canberra: NHMRC, 2003.

4. Commonwealth Department of Aged Care. National Physical Activity Guidelines for Australians. Canberra: Commonwealth Department of Health and Aged Care, 2002. 